\title{
Isolation of amygdalin epimer at high diastereomeric purity and its structural characterization by spectroscopic and Q-TOF LC-MS methods
}

\author{
Pshtiwan Raheem Sabır ${ }^{(1)}$, İrfan Çapan ${ }^{2,3 *}$, Ayhan İbrahim Aysal ${ }^{3}$ \\ and Süleyman Servi ${ }^{4}$ \\ ${ }^{1}$ Garmian University, College of Education, Chemistry Department, Kalar, Sulaymaneyah-Iraq \\ ${ }^{2}$ Gazi University, Technical Sciences Vocational College, Department of Polymer Technology, 06560 \\ Ankara-Türkiye \\ ${ }^{3}$ Gazi University, Faculty of Pharmacy, Department of Pharmaceutical Chemistry, Ankara- Türkiye \\ ${ }^{4}$ Firat University, Faculty of Science, Department of Chemistry, 23169 Elazlğ-Türkiye
}

(Received May 15, 2021; Revised August 6, 2021; Accepted August 11, 2021)

\begin{abstract}
Amygdalin, a cyanogenic glycoside mostly found in the bitter almond kernel, plays an important role in conventional and modern medicine applications. The high diastereomeric purity amygdalin was isolated with chromatographic purification methods and recrystallization. Amygdalin and neoamygdalin were separated chromatographically using the porous graphitic carbon column. Identification and confirmation of each molecule was performed with the ESI Quadrupole Time of Flight system coupled with a reversed phase LC.
\end{abstract}

Keywords: Amygdalin; neoamygdalin; cyanogenic glycoside; LC-MS Q-TOF; chromatography. (C) 2021 ACG Publications. All rights reserved.

\section{Introduction}

The bitter almond kernel has a high commercial value for the food and cosmetics industries. Amygdalin, one of the common cyanogenic glycosides, is found in bitter almond and peach kernels (Rosaceae family), while prunasin is found in wild cherry bark. The main bioactive components of bitter almond (Prunus amygdalus amara) are amygdalin, prunasin, flavonoids, and phenolic acids [1-3]. Furthermore, almond kernels have been used in traditional medicine to treat many diseases such as asthma, nausea, leprosy, bronchitis, and leukoderma [4].

The mandelonitrile carbon of the natural amygdalin has the $R$-configuration while the neoamygdalin has the $S$-configuration (Figure 1). These compounds are diastereomer due to not mirror

\footnotetext{
* Corresponding author E-Mail: irfancapan@gazi.edu.tr
} 
images of each other. The configuration of only one stereogenic center of the aglycone unit is different, so the amygdalin and neoamygdalin are the epimers of each other [5,6]. Due to the different physical properties, these epimers can be separated from each other using different methods. Ten stereogenic centers of the gentiobiose fragment have the same configuration in these diastereomers. They do not easily become isomerized, but epimerization of mandelonitrile carbon occurs in the presence of aqueous solvents or a weak basic medium [7-9].

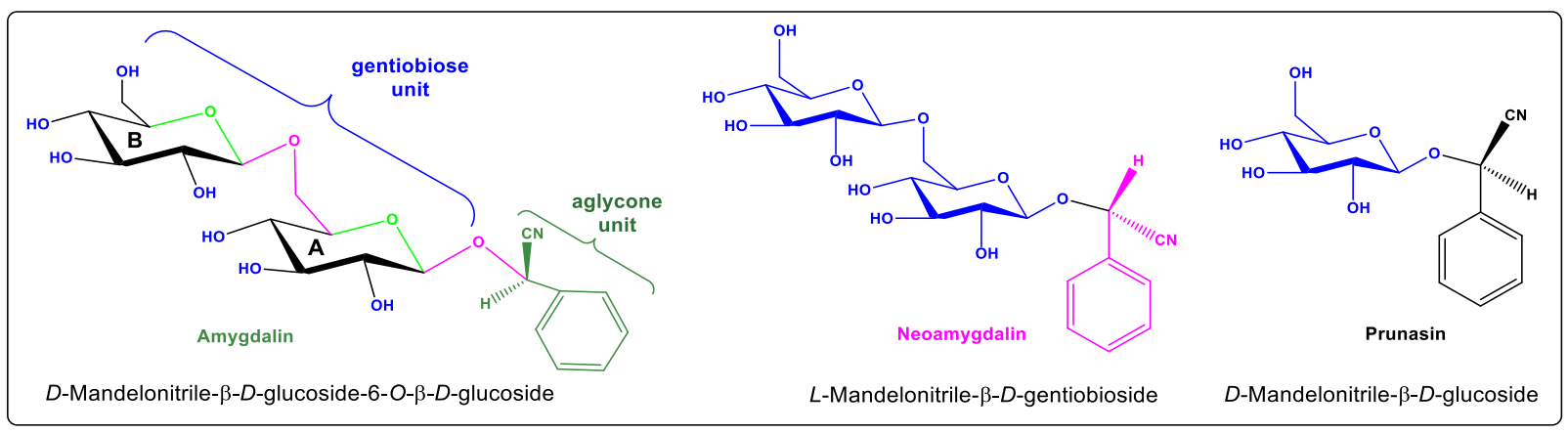

Figure 1. The stereochemical structures of amygdalin, neoamygdalin, and prunasin as cyanogenic glycosides.

There are many studies on the extraction of amygdalin from the foods and qualitative-quantitative analyses of the cyanogenic glycosides using chromatographic techniques as GC, LC, and HPLC-MS [1012]. However, there are few studies on the isolation of amygdalin from bitter almond kernels in stereochemical purity. The use of amygdalin has been the subject of considerable controversy in cancer treatment. However, neoamygdalin has no antitumor activity. Therefore, separating neoamygdalin has become an important factor in evaluating amygdalin-containing drugs [7, 8]. Many researchers are making efforts to separate the amygdalin epimers. So far, attempts to separate neoamygdalin from the epimer mixture using LC and HPLC methods have been reported [6, 11-15]. Also, Gas chromatography and capillary electrophoresis are used as practical analytical methods for the separation of neoamygdalin [16].

Cyanogenic glycosides are typically $O-\beta$-glycosides of $\alpha$-hydroxynitriles and are relatively nontoxic to most organisms [17]. However, amygdalin produces the poisonous substance HCN, which is decomposed by enzymes [18]. The cyanide released from the hydrolysis of amygdalin is cytotoxic. It was postulated that this action is selective against cancerous cells because normal cells convert the cyanide to benign thiocyanate via rhodanese, but this theory has not been proven in humans [19-24].

Although it is known that amygdalin has some pharmacological effects, many aspects of amygdalin have not been adequately investigated. Since its metabolism product is cytotoxic HCN, there is still controversy about its healing effect on human health both traditional and modern medicine [2029]. For this reason, systematic research on the pharmacological mechanism of amygdalin and the development of antitumor drugs may have a significant application value in the future.

Given its pharmacological and industrial importance, an easy and simple method is necessary to isolate the high purity amygdalin from natural products. Therefore, we aimed to develop a method to isolate the high diastereomeric purity amygdalin from bitter almond kernels. The structural characterization was performed using ${ }^{1} \mathrm{H},{ }^{13} \mathrm{C}-\mathrm{NMR}$, ATR-FTIR, and UV-VIS spectral techniques. The identification of amygdalin and neoamygdalin was carried out ESI Quadrupole Time-of-Flight system coupled with reversed-phase LC.

\section{Experimental}

\subsection{Materials and Methods}

All of the chemicals and solvents were purchased from commercial sources and purified-dried with classical methods. The melting point was determined by the Perkin-Elmer differential scanning calorimetry (DSC) apparatus. The Heidolph 4001 rotary evaporator was used to remove the solvents under 
Isolation of amygdalin from bitter almond kernel

reduced pressure. The UV-VIS spectrum was recorded with the Ocean Optics HR4000CG-UV-NIR highresolution spectrometer. The ATR-FTIR spectra were taken with the Perkin-Elmer Spectrum Two Spectrometer, and the band positions were presented as wavenumbers $\left(\mathrm{cm}^{-1}\right)$. The NMR spectra were recorded on Bruker $400-\mathrm{MHz}$ spectrometer using both $\mathrm{D}_{2} \mathrm{O}$ and DMSO- $d_{6}$ solvents. Chemical shifts were reported in ppm (parts per million) values relative to tetramethylsilane (TMS) as the internal standard. The applications of thin-layer chromatography (TLC) were performed with pre-coated $0.2 \mathrm{~mm}$ Merck Kieselgel $60 \mathrm{~F}_{254}$ aluminum sheets, and silica gel $60(0.063-0.200 \mathrm{~mm})$ was used for column chromatography (CC).

The applied procedures for isolation of pure amygdalin are summarized in Figure 1. Each of the extraction and purification methods is described in detail below.

\section{2. Sample Preparation}

The bitter almond kernels (Prunus amygdalus var. Amara) were collected in the Elazig province of Turkey. After the raw kernels were kept in hot water for 10 minutes, their peels were taken out, dried at room temperature, and scalded kernels were obtained. The scalded samples were next placed in a pot, heated by stirring for 10 minutes until they turned yellow, and the fried kernels were obtained. Thus, the bitter almond kernels were divided into three different parts as raw, boiled, and stir-fried kernels. The classified kernels were powdered with a mortar and used in the solid-liquid extractions.

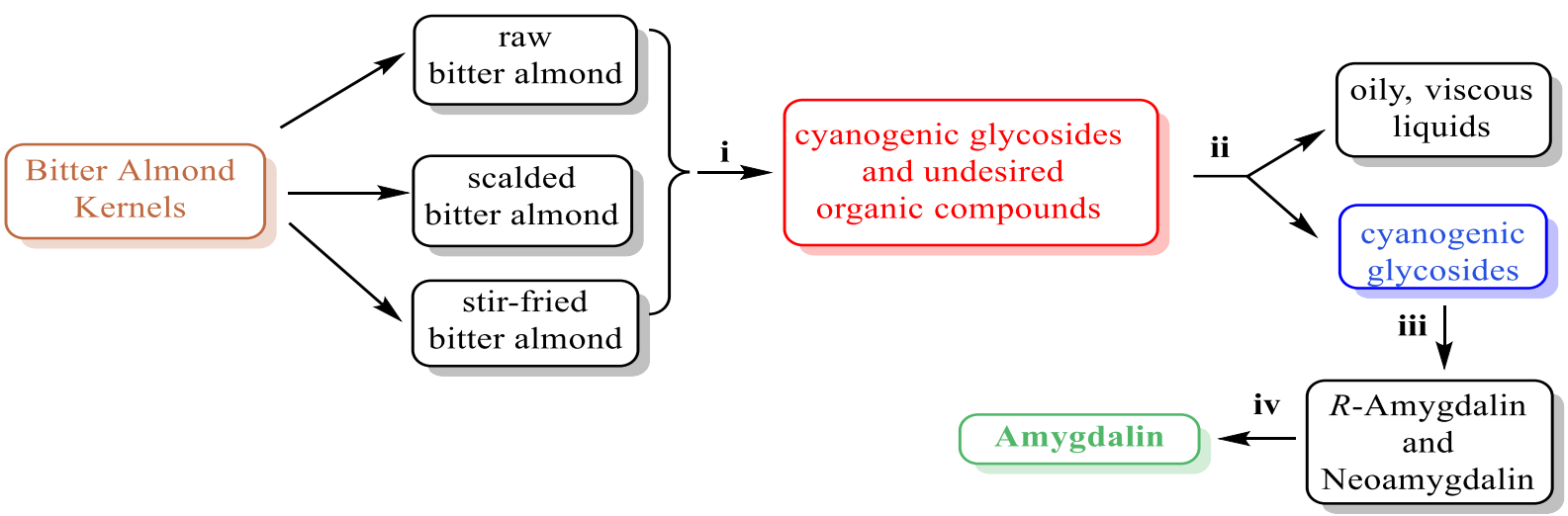

Figure 2. The steps of methods used in the isolation of amygdalin (i) SLE methods; (ii) LLE or decantation process with apolar solvents; (iii) column chromatography; (iv) recrystallization of the diastereomeric mixture with ethyl acetate.

\section{3. The Solid-Liquid Extraction (SLE) Methods}

\section{3. 1. Soxhlet Extraction Method}

Fifty grams of classified bitter almond kernels powders were put into the thimble, and then they were placed inside the Soxhlet extractor chamber. Then, $750 \mathrm{~mL}$ of ethanol was added into the single neck round-bottom flask. The Soxhlet extraction was continued for about 30 hours until 60 cycles at the boiling point of ethanol. The extract was concentrated until about $50-60 \mathrm{~mL}$ by evaporation under reduced pressure and used at the LLE and decantation methods.

\section{3. 2. Reflux Extraction Method}

Fifty grams of the stir-fried bitter almond kernel powders were placed in the flat round bottom flask, and $750 \mathrm{~mL}$ of ethanol was added. At the boiling point of the ethanol, the mixture was refluxed with constant stirring for approximately 3 hours. The hot mixture was filtered after the reflux was 
complete. When the resulting solution was held overnight in the deep-freezer, a white solid was formed and removed by filtrating from the solution. The solution was evaporated at reduced pressure until it remained around $50-60 \mathrm{~mL}$ using the rotary evaporator. The obtained concentrate extract was used during liquid-liquid extraction and decantation process.

\section{4. The Liquid-Liquid Extraction (LLE)}

The concentrated ethanol phase was extracted with twice $50 \mathrm{~mL}$ of $n$-hexane. The $n$-hexane layer was the upper phase, the ethanol layer which was the bottom phase was extracted with twice $50 \mathrm{~mL}$ of petroleum ether. The petroleum ether layer was the upper phase, the ethanolic layer which was the bottom phase was used for the next chloroform extraction. As soon as $100 \mathrm{~mL}$ of chloroform was added to the ethanol phase, a precipitate was formed. The occurred solid was removed from the solution by filtration. The final solid was firstly dried at room temperature, then in the vacuum oven, and remained in the vacuum dryer until the analysis was carried out. Later, this substance was used in TLC and CC analyses (Figure S1).

\section{5. The Decantation Method}

As the second method, the decantation process was used to remove the unwanted organic compounds from the ethanolic extracts. For this purpose, $n$-hexane, petroleum ether, and chloroform solvents were chosen. $50 \mathrm{~mL}$ of $n$-hexane was added to the concentrated extract obtained after SLE extractions. The $n$-hexane phase contains undesirable compounds while the bottom layer contains cyanogenic glycosides. The $n$-hexane phase was removed by decantation. As soon as $50 \mathrm{~mL}$ of petroleum ether was added over the remaining ethanol phase, a precipitate was obtained. The upper solution phase and precipitate were separated by decantation. The obtained precipitate was washed with three times 50 $\mathrm{mL}$ of chloroform. The final solid was used for TLC and CC analyses after drying (Figure S2).

After the LLE and decantation processes, the remaining ethanol phase was precipitated with diethyl ether and small amounts of cyanogenic glycosides were obtained. This solid material was used for TLC and CC analyses, after drying with the vacuum desiccator.

\section{6. Separation of Epimers by Column Chromatography}

Many tests were performed to determine the solvent mixture and ratio at which the best separation occurred on TLC. The chloroform/methanol $(2: 1, \mathrm{v} / \mathrm{v})$ solvent mixture and ratio gave the best result for the separation of epimers. $1.30 \mathrm{~g}$ of solid sample was injected into the column containing $52.0 \mathrm{~g}$ of silica gel, and chromatographic separation was performed using $350 \mathrm{~mL}$ of the solvent system as eluent. The $10 \mathrm{~mL}$ of the sample was collected into each beaker. After TLC analysis, the same substances were combined, and the solvents were evaporated in a vacuum. The resulting solid was recrystallized from ethyl acetate. Pure amygdalin was kept in an amber-colored glass bottle and stored at $4{ }^{\circ} \mathrm{C}$ before the analysis.

\section{7. Analysis of the Thermoanalytical Curves of The Samples}

The thermoanalytical curves, which characterize the thermal behavior of amygdalin, were obtained in dynamic conditions of temperature at a heating rate of $10^{\circ} \mathrm{C} \mathrm{min}^{-1}$ and in the atmosphere of nitrogen. From each sample, $3.70 \mathrm{mg}$ material was placed into a container for the special analyses, and the reference container was used for control. The sample was heated at $50{ }^{\circ} \mathrm{C}$ temperature under a nitrogen atmosphere. Oxygen gas was injected into the instrument until it reached $310{ }^{\circ} \mathrm{C}$ temperature. The oxygen flow rate through the instrument was $50 \mathrm{~mL} \mathrm{~min}^{-1}$ during this dynamic process while the heat flow rate was $10^{\circ} \mathrm{C} \min ^{-1}[30]$. 
Isolation of amygdalin from bitter almond kernel

\section{8. LC-MS Q-TOF Instrumentation and Conditions}

The analysis was carried out on the Agilent 1260 series HPLC system coupled with the Agilent iFunnel Q-TOF system. The HPLC unit consisted of a Binary pump (G1312B) with online degasser, HiP sampler (G1367E), Column Compartment (G1316A), and UV (G1314F) detector. The LC parameters were $0.5 \mathrm{ml} / \mathrm{min}$ isocratic flow of 15:85 (0.1\% formic acid water: methanol), 1 ul injection, column temperature $40^{\circ} \mathrm{C}$ and UV was set to $220 \mathrm{~nm}$ with $0.5 \mathrm{sec}$. response time. The column used for the analysis was Thermo Scientific Hypercarb Porous Graphitic Carbon $(2.1 \mathrm{~mm}$ x $100 \mathrm{~mm}$ x $5 \mu \mathrm{m})$. Run time was 6 $\min [6]$.

The MS part used for analysis and identification of compounds was Agilent G6550A Q-TOF with Dual AJS ESI source. The acquisition and data analysis were done by MassHunter software. The MS parameters: Source gas temperature $250{ }^{\circ} \mathrm{C}$, gas flow $14 \mathrm{~L} / \mathrm{min}$, Nebuliser $30 \mathrm{psig}$, Sheath gas temperature $320^{\circ} \mathrm{C}$, Sheath gas flow $10 \mathrm{~L} / \mathrm{min}$, capillary voltage $1500 \mathrm{~V}$, Nozzle voltage $500 \mathrm{~V}$, Fragmentor voltage $400 \mathrm{~V}$. Data acquisition was done in a negative ionization mode with MS and Targeted MS-MS mode. The parameters were $\mathrm{m} / \mathrm{z}$ range 50-1000 amu with the scan rate of $1 \mathrm{spectrum} / \mathrm{sec}$ for MS, $2 \mathrm{spectra} / \mathrm{sec}$ for MS-MS mode. The product ion profile was achieved by using fixed collision energies of 10 and 20 $\mathrm{eV}$. The data were evaluated for molecular ions and product ions for the identification of compounds via Metlin Metabolite Database and reference studies.

\section{Results and Discussion}

\subsection{Chemistry}

The extraction and purification methods are critical operations for isolating organic compounds from plants and foods. The selection of solvents used in these processes is very important in isolating the target compound from a natural product. Amygdalin is slightly soluble in alcohol at room temperature while easily dissolving in acetic acid, hot alcohol, and water [31]. Similarly, it is well soluble in polar aprotic solvents like DMSO and DMF. Although it is common to use the methanol-water mixture or only water in amygdalin extraction processes, it is a disadvantage that amygdalin is epimerized to neoamygdalin in aqueous environments. All of the solvents were purified and dried to prevent epimerization in this study.

Conventionally, the solid-liquid extraction (SLE) processes of pharmaceutical molecules are decoction in boiling water. Although a certain amount of amygdalin is epimerized to neoamygdalin in hot water, aqueous solvents, basic medium, and high temperature, the ethanol extraction does not require any operation to protect amygdalin from epimerization [6]. Because the obtained extract contained fewer undesirable substances and the extraction time was short, the reflux method was preferred for the amygdalin extraction in this study.

The extraction yields of cyanogenic glycosides from the natural products change considerably depending on the grinder [11], extraction methods, and the solvent [32]. Bitter almond kernels were classified as raw, boiled, fried. To obtain extracts of the classified kernels, both Soxhlet and the reflux methods were used. SLE processes were performed in anhydrous ethanol, a suitable solvent for cyanogenic glycosides. It was observed that a white solid formed when the obtained extract with the reflux process was kept in the deep-freezer overnight. ATR-FTIR and NMR spectra of this material are given in the Figure S3-5. This substance melted at room temperature and converted to an oily liquid. It was understood that this substance did not contain amygdalin and the other aromatic cyanogenic glycosides, according to spectral analysis. Since obtaining oily material was not the purpose of this study, removing a certain amount of this oily substance before purification operations were important. Additionally, a small amount of almond oil arises during the frying of the peeled-almond kernels, so the most amounts of cyanogenic glycoside were obtained from the stir-fried kernels in both extraction methods.

The obtained extracts from the SLE methods were subjected to liquid-liquid extraction (LLE) using different solvents. Since cyanogenic glycosides are not dissolved in non-polar solvents, to remove undesired components from the extract $n$-hexane, petroleum ether, and chloroform at LLE and decantation 
procedures were used. The ethanol phase was extracted with these solvents, and the phase was enriched in point of the cyanogenic glycosides amount, especially amygdalin.

Bitter almonds contain high levels of amygdalin (3-5\%) whereas sweet $(<0.05 \%$ amygdalin) and slightly bitter varieties ( $<0.2 \%$ amygdalin) have only trace levels of amygdalin [12].

$1.34 \mathrm{~g}$ of dry extract was obtained from $100.00 \mathrm{~g}$ of bitter almond after SLE and LLE process whereas $0.75 \mathrm{~g}$ of the epimer mixture was isolated after chromatographic separation. After the diastereomeric mixture was crystallized with ethyl acetate, $0.48 \mathrm{~g}(4.8 \mathrm{~g} / \mathrm{kg})$ of pure amygdalin was isolated as a white powder. The final compound was found to contain the high diastereomeric purity amygdalin according to the spectral data.

\section{2. Spectral Analyses}

In the first stage of structure characterization, the FT-IR, NMR spectrum, and the melting point of the standard amygdalin, which were obtained from internet sources, were used as the reference data [33]. The ATR-FTIR spectra obtained in this study are given in Figure S6-9. The amygdalin standard was not used at any stage of this study. The numbering system used to evaluate the NMR spectra of amygdalin and detailed ${ }^{1} \mathrm{H}$ and ${ }^{13} \mathrm{C}-\mathrm{NMR}$ spectra are given in Figure S10-16.

\section{2. 1. Analyses of the ATR-FTIR Spectra}

The A and B rings of amygdalin (Figure 1) have seven different hydroxyl groups. One of them is a primary alcohol, and the other six are the secondary alcohol functional groups. These have dense and broad bands between 3597-3300 $\mathrm{cm}^{-1}$ (Figure S7). When this region of the ATR-FTIR spectrum was carefully examined, $\mathrm{O}-\mathrm{H}$ stretching vibrations of five different hydroxyl groups that were not equivalent were observed. Of these, the stretching vibration at $3399 \mathrm{~cm}^{-1}$ shows a sharp band due to the intramolecular hydrogen bond while broad bands have been observed at 3598, 3513, 3461, and $3301 \mathrm{~cm}^{-}$ ${ }^{1}$ belonging to the $\mathrm{O}-\mathrm{H}$ stretching vibrations resulting from intermolecular hydrogen bonds.

The aromatic and aliphatic $\mathrm{C}-\mathrm{H}$ stretching vibrations were attributed to lower intensity absorptions at 2971 and $2893 \mathrm{~cm}^{-1}$, respectively. Although the stretching vibration belonging to the nitrile functional group of amygdalin is characteristic, it has a weak band in the ATR-FTIR spectrum. Due to the presence of the nitrile functional group, the band at $2260 \mathrm{~cm}^{-1}$ can be noticed in the spectra (Figure S8). Since the $\mathrm{C}-\mathrm{H}$ deformation vibration of the aromatic ring having five adjacent hydrogens was observed at $758 \mathrm{~cm}^{-}$ ${ }^{1}$, it confirmed that the benzene ring was the only substitute.

Amygdalin contains eleven non-equivalent C-O bonds. When the region between $1163-1022 \mathrm{~cm}^{-1}$ was carefully analyzed in the ATR-FTIR spectrum, eleven stretching vibration bands relating to C-O bonds were observed (Figure S9). Two of the four C-O-C bonds belong to endocyclic ethers while the other two are the stretching vibrations of exocyclic ethers. The remaining seven are $\mathrm{C}-\mathrm{O}-\mathrm{H}$ bonds.

\section{2. 2. Analysis of the ${ }^{1} H$-NMR Spectra}

The ${ }^{1} \mathrm{H}-\mathrm{NMR}$ spectra of the amygdalin and cyanogenic glycosides have been generally taken in DMSO- $d_{6}$. In this study, ${ }^{1} \mathrm{H}$ and ${ }^{13} \mathrm{C}-\mathrm{NMR}$ spectra taken in $\mathrm{D}_{2} \mathrm{O}$ and DMSO- $d_{6}$ solvents were analyzed. Twenty-seven proton-equivalent signals were observed in the ${ }^{1} \mathrm{H}-\mathrm{NMR}$ spectrum received in DMSO- $d_{6}$ (Figure $3 \mathrm{~A}$ ) whereas when the spectrum was taken with $\mathrm{D}_{2} \mathrm{O}$, twenty-two proton-equivalent signals were observed due to the proton-deuterium change (Figure 3B). When the ${ }^{1} \mathrm{H}-\mathrm{NMR}$ spectrum taken in DMSO$d_{6}$ was compared with that of taking in $\mathrm{D}_{2} \mathrm{O}$, all signals shifted to the low-fields. In the ${ }^{1} \mathrm{H}-\mathrm{NMR}$ spectra taken in both $\mathrm{D}_{2} \mathrm{O}$ and DMSO- $d_{6}$ solvents, the signal observed at about $1.00 \mathrm{ppm}$ was attributed to the impurity from the NMR device.

The ${ }^{1} \mathrm{H}-\mathrm{NMR}$ spectrum given in Figure 3C belongs to the extract obtained after LLE, and it contains a mixture of amygdalin and neoamygdalin. The $\mathrm{H}-7$ proton of neoamygdalin has an integration ratio of 0.26 at $6.09 \mathrm{ppm}$ while the $\mathrm{H}-7$ proton of amygdalin has an integration ratio of 1.00 at $6.02 \mathrm{ppm}$. According to this ${ }^{1} \mathrm{H}-\mathrm{NMR}$ spectrum, while the amygdalin amount is $79.4 \%$, the neoamygdalin amount is $20.6 \%$ in the mixture. When this spectrum was compared with the received in $\mathrm{D}_{2} \mathrm{O}$ (Figure $3 \mathrm{~B}$ ), the signal of aglycone proton (H-7), which leads to epimer formation, shifted to the lower area of about 0.18 
Isolation of amygdalin from bitter almond kernel

ppm for neoamygdalin. No signal belonging to neoamygdalin was observed in the ${ }^{1} \mathrm{H}-\mathrm{NMR}$ spectrum taken in the DMSO- $d_{6}$ solvent of the purified sample (Figure 3A). This situation confirmed that the aglycone proton is somewhat epimerized in water. Moreover, there was also no change in the chemical shift of the amygdalin H-7 proton.

The detailed assessment of ${ }^{1} \mathrm{H}-\mathrm{NMR}$ (Figure2B) taken in $\mathrm{D}_{2} \mathrm{O}$ solvent is given below. ${ }^{1} \mathrm{H}-\mathrm{NMR}$ $\left(400 \mathrm{MHz}, \mathrm{D}_{2} \mathrm{O}\right) \delta=7.46-7.44(\mathrm{H}-1$ and $\mathrm{H}-5, \mathrm{~m}, 2 \mathrm{H}) ; 7.39-7.37(\mathrm{H}-2, \mathrm{H}-3$, and $\mathrm{H}-4, \mathrm{~m}, 3 \mathrm{H}) ; 5.91(\mathrm{H}-7$, $\mathrm{s}, 1 \mathrm{H}$, for neoamygdalin); $5.74(\mathrm{H}-7, \mathrm{~s}, 1 \mathrm{H}$, for amygdalin); 4.07-4.04 (d, $J=12 \mathrm{~Hz}, 1 \mathrm{H}) ; 3.79-3.73(\mathrm{~m}$, $2 \mathrm{H})$; 3.60-3.55 (m, $2 \mathrm{H}) ; 3.50-3.46(\mathrm{~m}, 2 \mathrm{H}) ; 3.40-3.35(\mathrm{~m}, 2 \mathrm{H}) ; 3.34-3.30(\mathrm{~m}, 2 \mathrm{H}) ; 3.29-3.25(\mathrm{~m}, 2 \mathrm{H})$; 3.24-3.17 (m, 2H).

The epimer mixture containing the amygdalin and neoamygdalin diastereomers was purified using column chromatography and the amygdalin was isolated at high purity. In the ${ }^{1} \mathrm{H}-\mathrm{NMR}$ spectrum of amygdalin taken in the $\mathrm{D}_{2} \mathrm{O}$ solvent, the ortho coupled $\mathrm{H}-1$ and $\mathrm{H}-5$ aromatic protons were observed at $7.46 \mathrm{ppm}$ as the equivalent of two protons. However, the meta and para coupled aromatic protons $(\mathrm{H}-2$, $\mathrm{H}-3$, and $\mathrm{H}-4)$ resonated at $7.39 \mathrm{ppm}$ as a multiplet equivalent to three protons. The signal observed at $5.74 \mathrm{ppm}$ belongs to one proton equivalent benzylic Ar-CH-CN hydrogen. This aryl component is the group of aglycone having $\mathrm{R}$ and $\mathrm{S}$ epimer forms, which can exist by the epimerization assisted by basic or extreme temperature conditions. The S-epimerized $\mathrm{CH}-\mathrm{CN}$ proton signal appears in the lower field than the $\mathrm{CH}$ proton signal of the R-epimer [34].

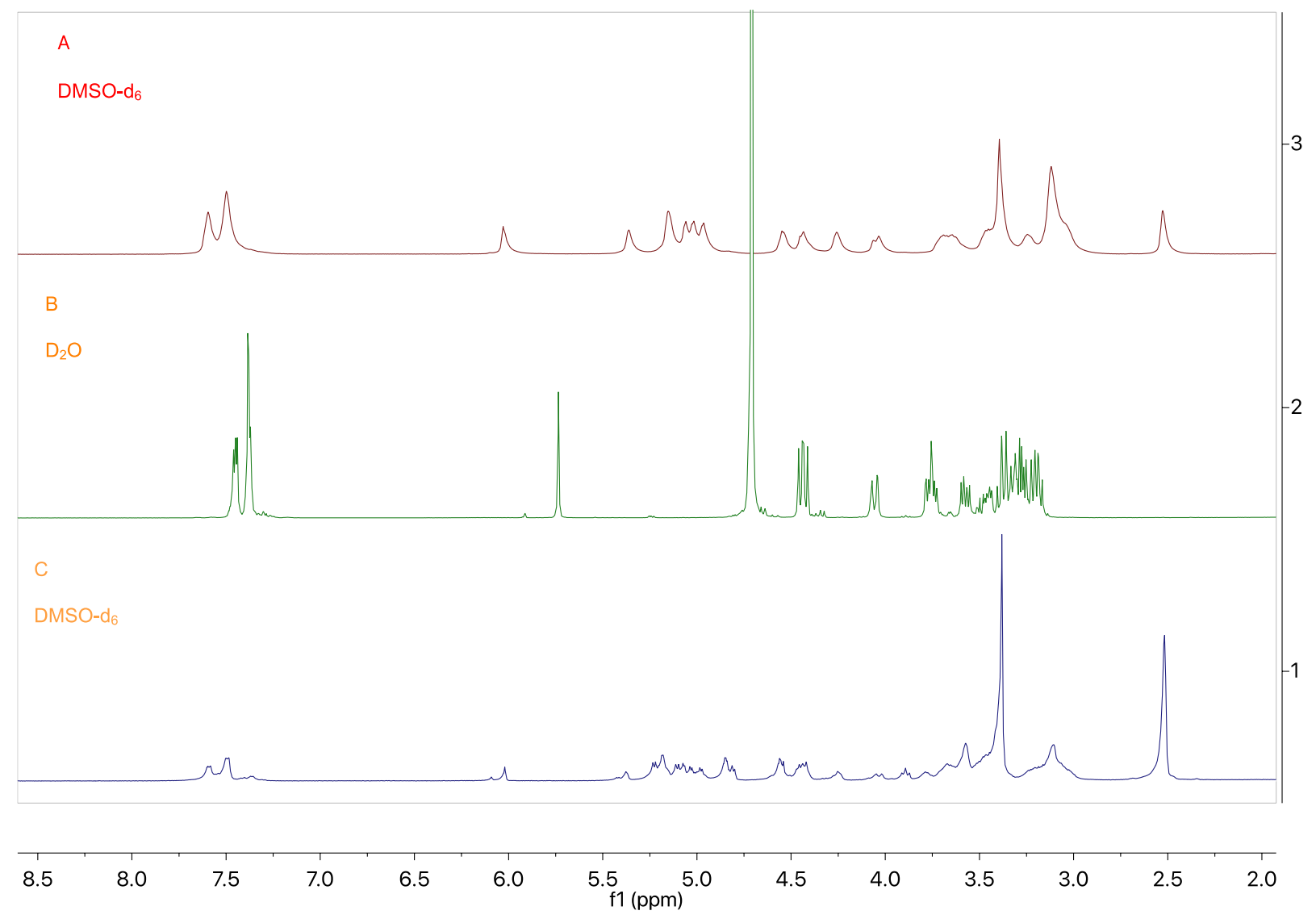

Figure 3. ${ }^{1} \mathrm{H}-\mathrm{NMR}(400 \mathrm{MHz})$ spectra of the amygdalin and its epimer were taken in different solvents; A: the spectrum in DMSO- $d_{6}$ of pure amygdalin obtained in this study; $\mathrm{B}$ : spectrum of the diastereomeric mixture in $\mathrm{D}_{2} \mathrm{O}$; $\mathrm{B}$ : the diastereomeric mixture in $\mathrm{D}_{2} \mathrm{O}$, and $\mathrm{C}$ : spectrum in DMSO- $d_{6}$ of the extract obtained after LLE.

The amygdalin, which is pure in solid form, was epimerized in the $\mathrm{D}_{2} \mathrm{O}$, and this was observed in the ${ }^{1} \mathrm{H}-\mathrm{NMR}$ spectrum with two different signals and different integration ratios. However, such an 
epimerization was not observed in the ${ }^{1} \mathrm{H}-\mathrm{NMR}$ spectrum of the same substance taken in the DMSO- $d_{6}$. Two different signals belonging to the H-7 proton of the aglycone unit were observed in the ${ }^{1} \mathrm{H}-\mathrm{NMR}$ spectrum taken in the $\mathrm{D}_{2} \mathrm{O}$ solvent (Figure 3B). The signal with an integration ratio of 0.03 at $5.92 \mathrm{ppm}$ belongs to neoamygdalin whereas the signal with an integration ratio of 1.00 at $5.74 \mathrm{ppm}$ belongs to the amygdalin. According to the ${ }^{1} \mathrm{H}-\mathrm{NMR}$ result, the rates of amygdalin and neoamygdalin were found in $97.1 \%$ and $2.9 \%$ in the sample, respectively. The fourteen proton signals observed as multiple signals between 4.07 and $3.15 \mathrm{ppm}$ belong to two glycopyranose rings. The eight proton signals were observed in the fairly narrow region of 3.40 to $3.34 \mathrm{ppm}$ [34]. The signal at $4.70 \mathrm{ppm}$ belongs to the proton residue in the $\mathrm{D}_{2} \mathrm{O}$.

\section{2. 3. Analysis of ${ }^{13} C$-NMR Spectra}

The ${ }^{13} \mathrm{C}$-NMR spectrum, which is taken in DMSO- $d_{6}$, given in Figure S11, 12 belongs to the extract obtained after LLE, and it contains the amygdalin and neoamygdalin mixture (Figure 4F). The seventeen different carbon signals were observed in two different ${ }^{13} \mathrm{C}$-NMR spectra taken in both $\mathrm{D}_{2} \mathrm{O}$ and DMSO$d_{6}$ solvents. While C-13 and C-17 carbons were observed as the same signal, two ortho and two meta carbons of the aromatic ring were observed as different signals. Except for C-3, C-7, C-14, C-16, and C20 , all of the other carbons resonated in low areas.

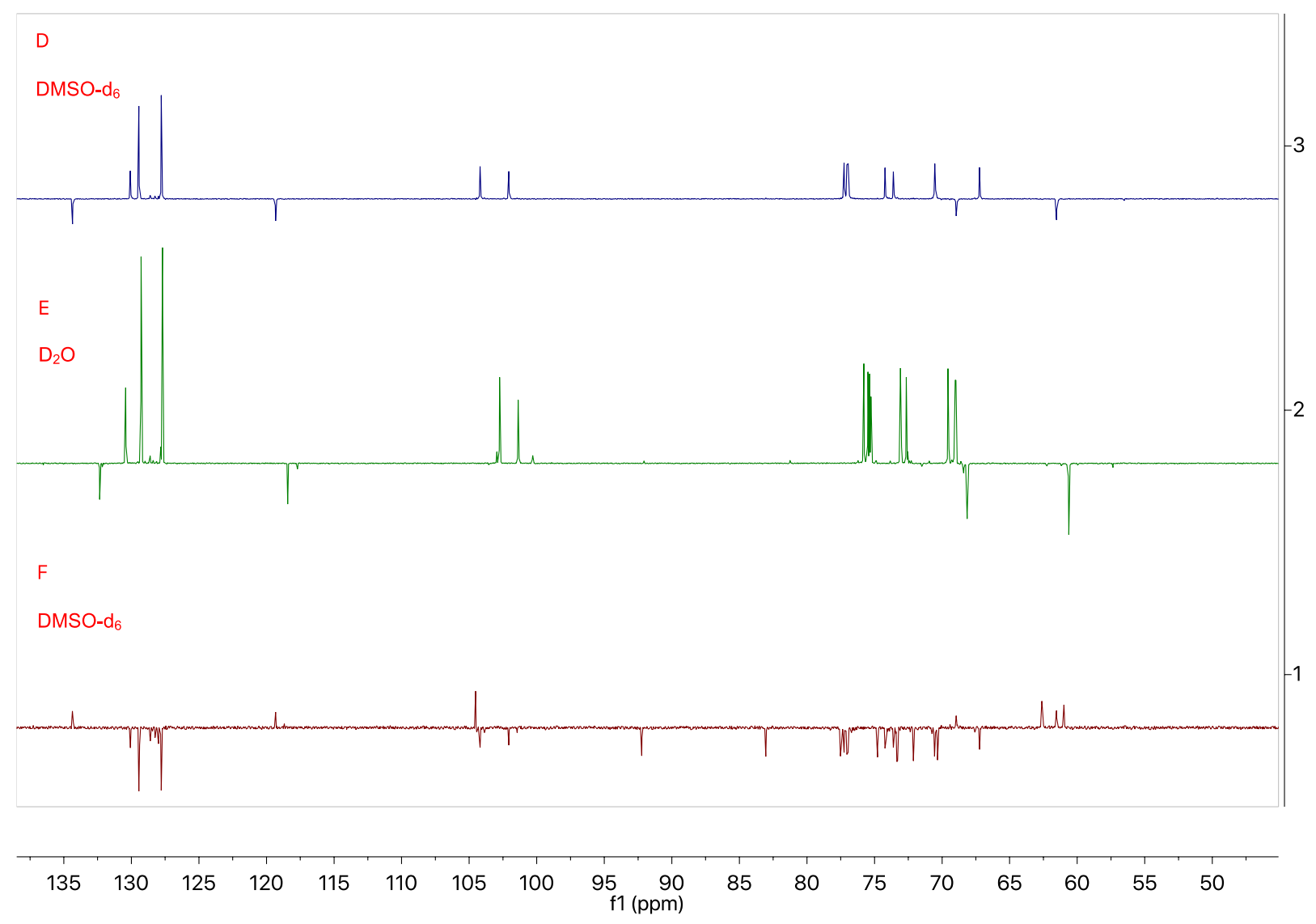

Figure 4. ${ }^{13} \mathrm{C}-\mathrm{NMR}, 100 \mathrm{MHz}$ spectra of the amygdalin, and its epimer were taken in different solvents; D: the spectrum in DMSO- $d_{6}$ of pure amygdalin obtained in this study; E: spectrum of the diastereomeric mixture in $\mathrm{D}_{2} \mathrm{O}$, F: spectrum in DMSO- $d_{6}$ of the extract obtained after LLE. 
Isolation of amygdalin from bitter almond kernel

Evaluation of ${ }^{13} \mathrm{C}$-NMR spectra taken in DMSO- $d_{6}$ (Figure 4D) and $\mathrm{D}_{2} \mathrm{O}$ (Figure 4E) solvents are given below. The first values belong to the carbon signals in $\mathrm{D}_{2} \mathrm{O}$ while the values in brackets are the chemical shift values of the carbon signals in the spectrum received in DMSO-d6.

${ }^{13} \mathrm{C}-\mathrm{NMR}, 100 \mathrm{MHz}, \mathrm{D}_{2} \mathrm{O}$ (DMSO-d6) ppm, $\delta 132.35$ (134.36), C-6, aromatic quaternary carbon; 130.42 (130.08), C-3, para; 129.28 (129.45), C-2 and C-4, meta; 127.70 (127.79), C-1 and C-5, ortho; 118.43 (119.31), C-8, CN; 102.74 (104.19), C-15; 101.38 (102.07), C-9; 75.79 (77.25), C-19; 75.48 (77.05), C-17; 75.36 (77.02), C-11 and C-17; 73.08 (76.95), C-16; 72.64 (75.23), C-10; 69.56 (70.56), C12; 69.03 (68.96), C-18; 68.97 (67.24), C-7 benzylic carbon; 68.14 (61.53), C-14; 60.61 (56.36) C-20.

At 132.5 and $118.7 \mathrm{ppm}$, the carbon resonances show the negative phase in the APT-NMR spectrum and are less intense than the other carbon signals. Therefore, these signals were assigned to two quaternary carbons, C-6 and C-8, respectively. Similarly, the carbon resonances at 68.14 and $60.61 \mathrm{ppm}$ were assigned to the two methylene carbons, respectively $\mathrm{C}-14$ and $\mathrm{C}-20$. The remaining carbon signals indicate the positive phase in the APT-NMR spectrum and confirm them as odd and multiple carbon resonances. Since amygdalin possesses no methyl groups, these remaining carbon signals must arise from methine carbons. The aromatic carbon signal at $130.42 \mathrm{ppm}$ can be assigned to the para- $\mathrm{CH}$ carbon. The remaining $\mathrm{CH}$ carbon signals at 127.70 and 129.28 ppm represent two carbon signals and arise from the ortho and meta carbons [34].

\section{2. 4. Analyses of the UV-VIS}

The UV-VIS spectrum of the isolated amygdalin was taken in methanol at the concentration of $75 \mu \mathrm{g} \mathrm{mL}-1$ (Figure S17). Mainly $218 \mathrm{~nm} \sigma-\sigma^{*}$ transitions, and $\pi-\pi *$ transitions of $256 \mathrm{~nm}$ aromatic rings were observed. These maximum absorptions were found to be quite similar to those reported at 184 , 203 , and $256 \mathrm{~nm}$, attributed to aromatic $\pi-\pi^{*}$ transitions. The maximum absorption of the nitrile group was not noticed due to its low intensity [35].

\section{2. 5. Thermal Analysis of the Differential Scanning Calorimetry Curves}

The DSC curve (Figure 5A) showed a large, sharp endothermal peak for the $97.1 \%$ purity amygdalin in the temperature range of $207.9-224.9^{\circ} \mathrm{C}$. The temperature that started to melt the amygdalin was $207.9{ }^{\circ} \mathrm{C}$. After melting, thermal decomposition began immediately. This curve also shows endothermic peaks of some impurities. The amygdalin stereoisomers (Figure 5B) showed a large, broad endothermal peak in the temperature range of $203.8-236.0^{\circ} \mathrm{C}$. The temperature that begins to melt the amygdalin stereoisomers is $203.8{ }^{\circ} \mathrm{C}$. The DSC, bends a broad endothermic peak at $223.1{ }^{\circ} \mathrm{C}$, corresponding to the maximum melting rate. According to the DSC curve, pure amygdalin (Figure 5C) has a melting point of $218{ }^{\circ} \mathrm{C}$. The purity of the amygdaline was confirmed with a sharp endothermic peak at $220.7^{\circ} \mathrm{C}$, which corresponds to the maximum melting rate. Also, the endothermic or exothermic peaks belonging to any impurity were not observed in this curve. This melting point is close to the values given in the literature $\left(223-226^{\circ} \mathrm{C}\right)$, but it is more accurate compared to them $[31,36]$. 


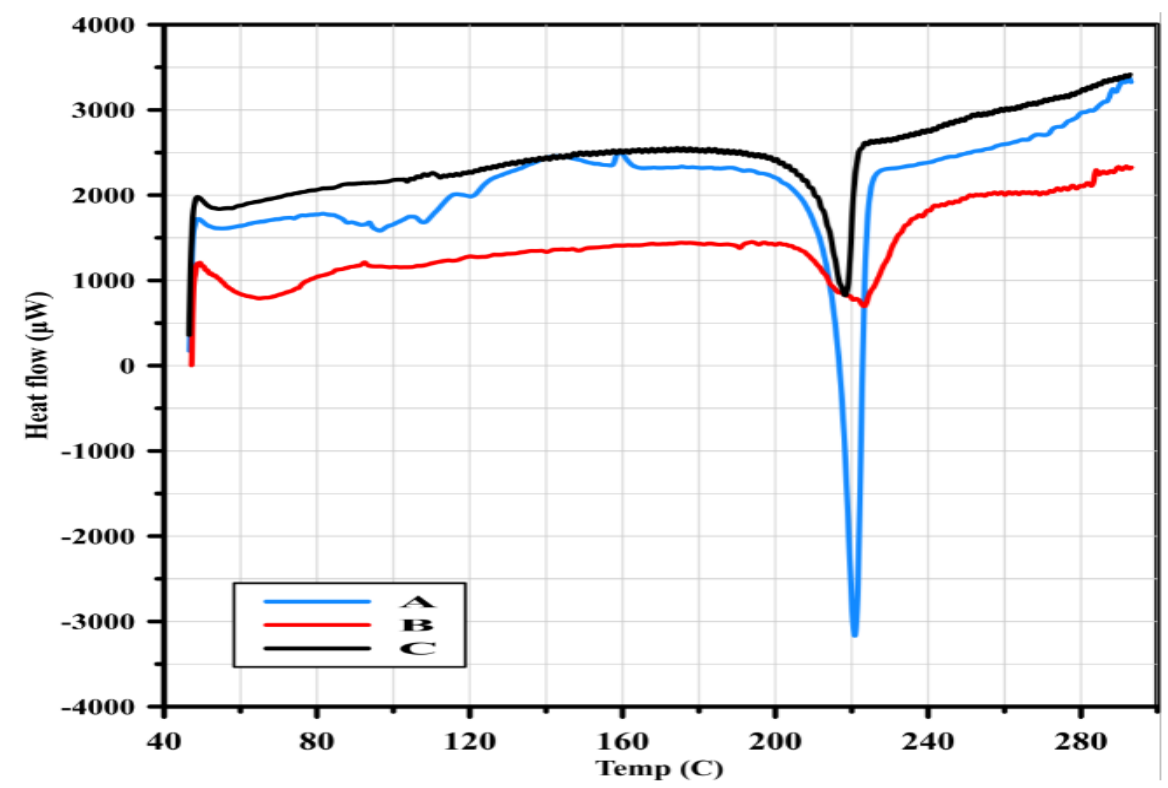

Figure 5. The Differential Scanning Calorimetry curves; (A) after from column chromatography; (B) the mixture of the amygdalin and neoamygdalin stereoisomers; $(\mathrm{C})$ pure amygdalin obtained after from recrystallization with ethyl acetate.

\section{6. Analysis of the LC-MS Q-TOF}

The UV signal and corresponding MS responses were examined for MS and MS-MS information. ESI generated ions of the sample corresponding to the amygdalin were compared with databases for characteristic amygdalin ions and they were identical to each other. Experimental values for ions used for identification of the compound were having mass error less than $5.0 \mathrm{ppm}$ with theoretical amygdalin ions. The chromatogram (Figure S18) shows the total ion chromatogram of the sample injection in MS-MS mode. The retention times at 1.46 and 4.12 minutes show the targeted mode run where collision energies were applied. The extracted ion chromatogram (Figure 6) of 456.1520 showed the retention of amygdalin and its epimer. The retention times of 1.46 and 4.12 belong to neoamygdalin and amygdalin, respectively [6]. 456.1522 ion shows a neoamygdalin precursor with a mass error of $-2.31 \mathrm{ppm}$ (Figure S19). The isotopic distribution of neoamygdalin is shown in (Figure S20) with a mass error of $-2.31 \mathrm{ppm}$ for $456.1517,0.96 \mathrm{ppm}$ for 457.1549 , and $-0.23 \mathrm{ppm}$ for 458.1567 . The isotopic distribution of amygdalin is shown in (Figure S21, 22) with a mass error of $-1.4 \mathrm{ppm}$ for $456.1517,0.08 \mathrm{ppm}$ for 457.1545 , and 1.94 ppm for 458.1557.

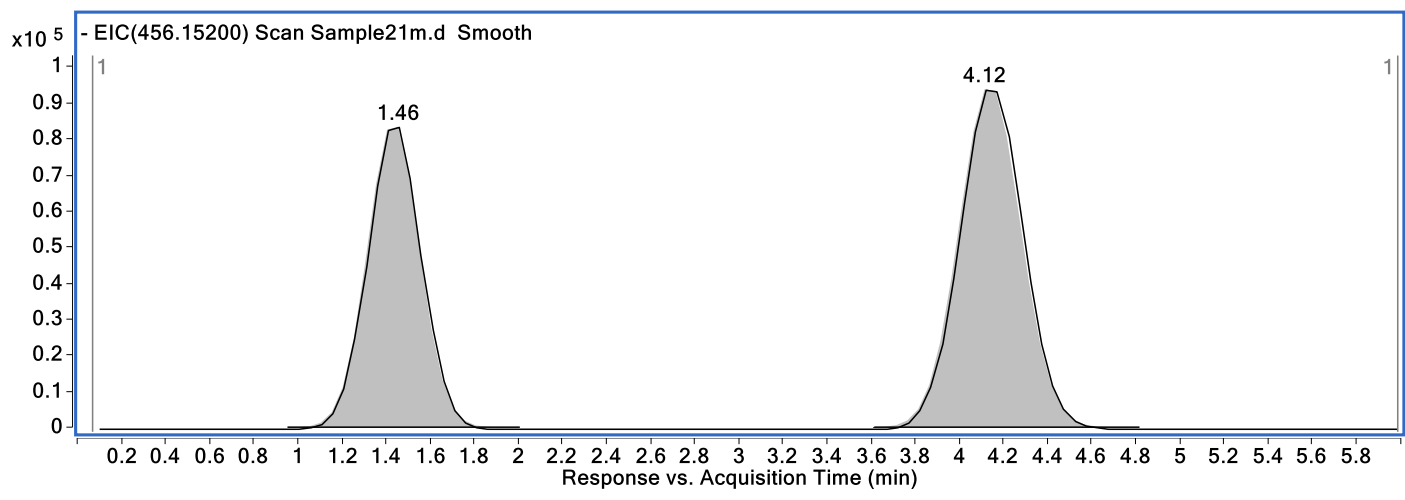

Figure 6. Extracted Ion of 456.1520 showing amygdalin and its epimer neoamygdalin 
Isolation of amygdalin from bitter almond kernel

Figure 7 shows the Total Ion Chromatogram (TIC) of the sample injected in Targeted MS-MS mode. In targeted mode, Quadrupole isolates the selected precursor ion at predefined retention time. The precursor of neoamygdalin/amygdalin at retention times 1.47 and 4.27 was selected via quadrupole and fragmentation occurred using nitrogen as a collision gas with a $10 \mathrm{eV}$.

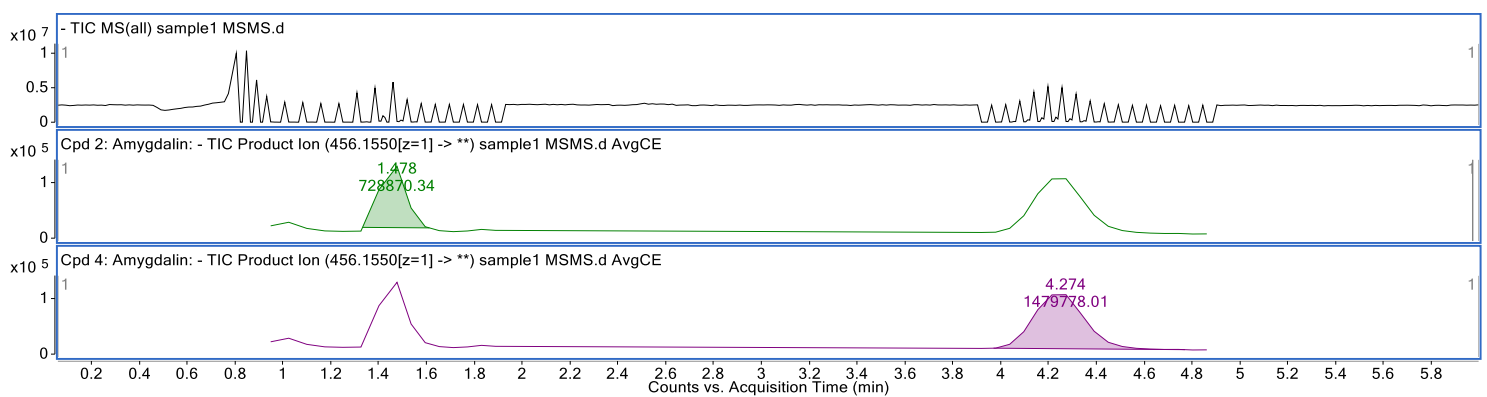

Figure 7. TIC of MS-MS of 456.1550 ions at RT 1.41 and 4.20 with collision energies $10 \mathrm{eV}$.

The below part of Figure 7, Cpd 2, and Cpd 4 show an Extracted Ion Chromatogram of 456.1550 ion at retention time values 1.47 and 4.27. Those are the retention time of amygdalin and its epimer neoamygdalin. Figure 8 indicates the fragmentation pattern of the isolated ion of 456.1504 , neoamygdalin precursor with a mass error of $1.53 \mathrm{ppm}$ (calculated value is 456.1511). The upper part A shows the experimental spectra acquired sample run at retention time 1.47 minute. The library part $\mathrm{C}$ is shown at the bottom and the middle part B shows the comparison of library and experimental spectra of amygdalin. Product ion at retention time $1.42 \mathrm{~min}$. is matched perfectly with the library spectrum of amygdalin.

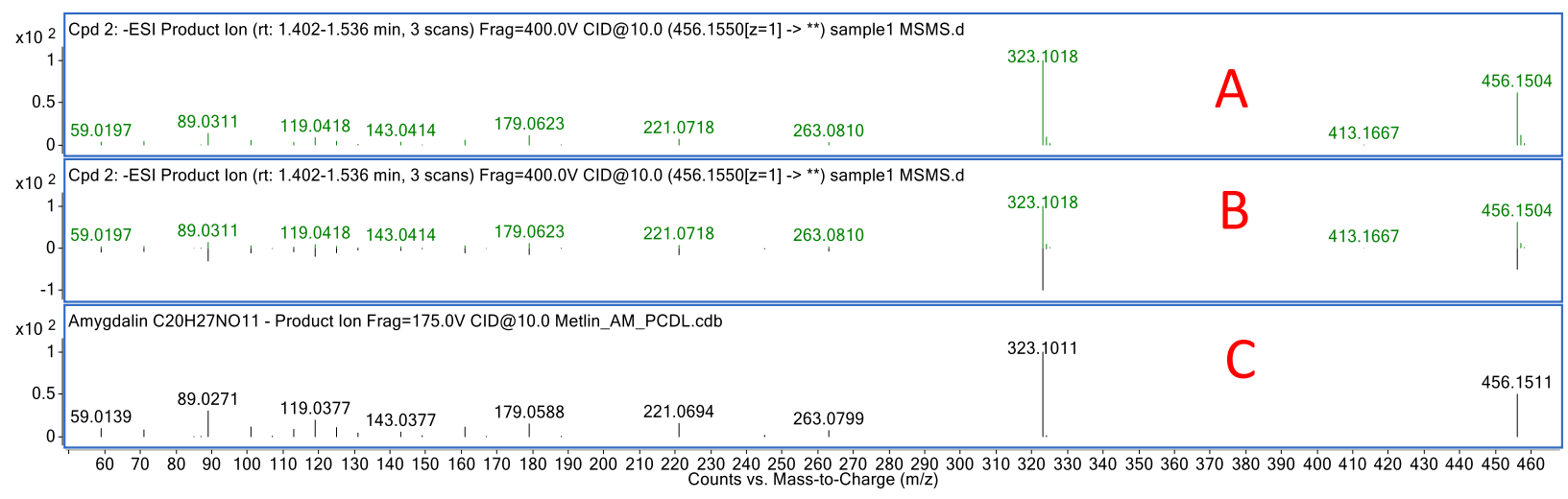

Figure 8. Product ion spectra (A) of 456.1550 ion at retention time 1.41 with collision energy $10 \mathrm{eV}$ and library spectra $(\mathrm{C})$ of amygdalin.

Figure 9 shows the fragmentation pattern of the isolated ion of 456.1506, amygdalin precursor with a mass error of $1.09 \mathrm{ppm}$ (calculated value is 456.1511). The upper part A shows the experimental spectra acquired sample run at retention time 4.27. The library spectra part $\mathrm{C}$ is shown at the bottom and the middle part B shows the comparison of library and experimental spectra of amygdalin. Product ion at retention time 4.27 is matched perfectly with the library spectrum of amygdalin. 
Sabir et al., J. Chem.Metrol. 15:2 (2021) 172-185

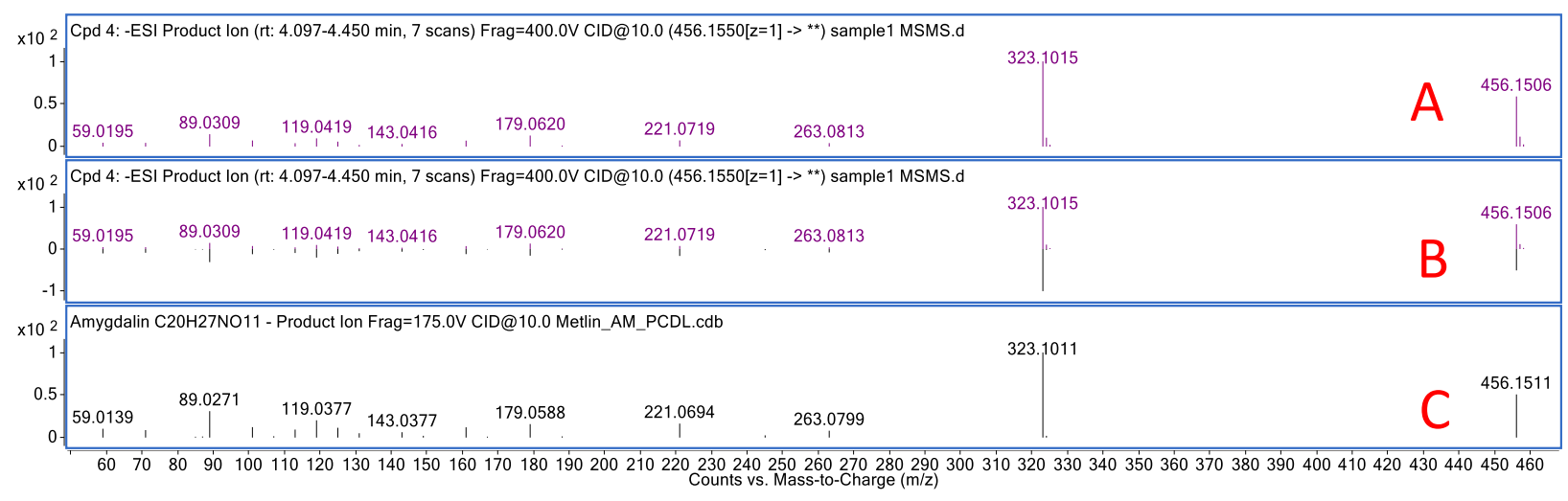

Figure 9. Product ion spectra (A) of 456.1506 ion at retention time 4.27 with collision energy $10 \mathrm{eV}$ and library spectra $(\mathrm{C})$ of amygdalin.

\section{Conclusions}

Generally, in analytical methods used to determine the amount of amygdalin, the epimers have been analyzed together and evaluated. Furthermore, when the extraction and isolation process is performed in an aqueous or basic environment, the diastereomeric mixture resulting from epimerization cannot show the desired biological and physiological effects. This situation caused serious errors in the analysis of the amygdalin amount. At the same time, this is the main reason for the current controversy about its medical and pharmacological effects.

The reflux extraction is more efficient than the Soxhlet method for the extraction of amygdalin from the bitter almond kernels. Since the solid-liquid extractions of amygdalin were performed in the anhydrous ethanol, the epimerization did not occur. Ethanol is an ideal solvent for the extraction of amygdalin. The chromatographic, thermal, and spectroscopic methods were used to confirm the purity of amygdalin. All spectral data are consistent with the chemical structure of amygdalin. Also, all spectral and chromatographic data show satisfactory purity of the isolated amygdalin.

The amygdalin standard was not used at any stage of this study, but the high diastereomeric purity amygdalin, which will be used as the standard, was isolated using simple and economical methods. The acquired MS data, its isotopic pattern, and isotopic abundances, and product ion profiles were consistent with the product ion profiles of amygdalin and its epimer neoamygdalin at Metlin Metabolite Database.

In this study, a simple, precise, and relatively easy analytical method was developed for the separation and determination of amygdalin and neoamygdalin in bitter almond kernels.

\section{Acknowledgements}

We would like to thank Firat University Research Project Coordination Unit (Project Number FF.19.03) for the financial support of this study.

\section{Supporting Information}

Supporting information accompanies this paper on https://www.acgpubs.org/journal/journal-ofchemical-metrology

\section{ORCID}

Pshtiwan Raheem Sabır: 0000-0001-7655-5705

İrfan Çapan: 0000-0002-9555-1555

Ayhan İbrahim Aysal: 0000-0001-8048-8621

Süleyman Servi: 0000-0003-0827-8624 
Isolation of amygdalin from bitter almond kernel

\section{References}

[1] S. Čolić, G. Zec, M. Natić and M. Fotirić-Akšić (2019). Almond (Prunus dulcis) oil. In: Ramadan M. (Eds.), Fruit oils: chemistry and functionality. Springer, Cham., pp.149-180.

[2] S.M. Kerry Bone, Principles and practice of phytotherapy (2013). Modern herbal medicine, 2nd Edition ed., Churchill Livingstone, pp. 17-82.

[3] B. Moradi, S. Heidari-Soureshjani, M. Asadi-Samani and Q. Yang (2017). A systematic review of phytochemical and phytotherapeutic characteristics of bitter almond, Int. J. Pharm. Phytopharmacol. Res. 7 1-9.

[4] M. Qadir and K. Fatima (2017). Review on pharmacological activity of Amygdalin, Arch. Cancer Res. 5 10-12.

[5] T. Cairns, E. J. Froberg, S. Gonzales, W. S. Langham, J. J. Stamp, J. K. Howie, and D. T. Sawyer (1978). Analytical chemistry of Amygdalin, Anal. Chem., 50,317-322.

[6] M. F. Wahab, Z. S. Breitbach, D. W. Armstrong, R. Strattan and A. Berthod (2015). Problems and pitfalls in the analysis of Amygdalin and its epimer, J. Agric. Food Chem. 63, 8966-8973.

[7] Y. Takayama and S. Kawai (1984). Study on the prevention of racemization of Amygdalin, Chem. Pharm. Bull. 32 778781.

[8] J.Y. Koo, E.Y. Hwang, S. Cho, J.H. Lee, Y.M. Lee and S.P. Hong (2005). Quantitative determination of Amygdalin epimers from Armeniacae Semen by liquid chromatography, J. Chromatogr. B Biomed. Appl. 814 69-73.

[9] W.S. Joo, J. S. Jeong, H. Kim, Y. M. Lee, J. H. Lee and S. P. Hong (2006). Prevention of epimerization and quantitative determination of Amygdalin in Armeniacae semen with schizandrae fructus solution, Arch. Pharm. Res. 29 1096-1101.

[10] B.Y. Ge, H.X. Chen, F.M. Han and Y. Chen (2007). Identification of amygdalin and its major metabolites in rat urine by LC-MS/MS, J. Chromatogr. B Biomed. Appl. 857 281-286.

[11] S. Xu, X. Xu, S. Yuan, H. Liu, M. Liu, Y. Zhang, H. Zhang, Y. Gao, R. Lin and X. Li (2017). Identification and analysis of amygdalin, neoamygdalin and amygdalin amide in different processed bitter almonds by HPLC-ESI-MS/MS and HPLC-DAD, Molecules 22 1425-1435.

[12] J. Lee, G. Zhang, E. Wood, C. R. Castillo and A. E. Mitchell (2013). Quantification of amygdalin in nonbitter, semibitter, and bitter almonds (Prunus Dulcis) by UHPLC-(ESI) Qqq MS/MS, J. Agric. Food Chem. 61 7754-7759.

[13] E. Y. Hwang, J.H. Lee, Y.M. Lee and S.P. Hong (2002). Reverse-phase HPLC separation of D-amygdalin and neoamygdalin and optimum conditions for inhibition of racemization of amygdalin, Chem. Pharm. Bull. 50 1373-1375.

[14] K.Wasserkrug and Z. El Rassi (1997). High-performance liquid phase separation of glycosides. I. Reversed-phase chromatography of cyanogenic glycosides with UV and pulsed amperometric detection, J. Liq. Chrom. Relat. Tech. 20 335-349.

[15] I. Boháčová, S. Procházková and R. Halko (2019). Separation and determination of amygdalin and unnatural neoamygdalin in natural food supplementarys by HPLC-DAD, Food Addit. Contam. Part A. 36 1445-1452.

[16] C. Campa, Ph. Schmitt-Kopplin, T.R.I. Cataldi, S.A. Bufo, D. Freitag and A. Kettrup (2000) Analysis of cyanogenic glycosides by micellar capillary electrophoresis, J. Chromatogr. B Biomed. Appl. 739 95-100.

[17] M.A. Hughes, S.D. Barton, K. Nakanishi and O. Meth-Cohn (Eds.) (1999). Comprehensive natural products chemistry, Pergamon, Oxford, pp. 881-895.

[18] https://www.mskcc.org/cancer-care/integrative-medicine/herbs/amygdalin\#references-23 $\quad$ (accessed $27 \quad$ September 2020).

[19] D. M. Greenberg (1980). The case against laetrile: the fraudulent cancer remedy, Cancer 45 799-807.

[20] Y. Chen, J. Ma, F. Wang, J. Hu, A. Cui, C. Wei, Q. Yang and F. Li (2013). Amygdalin induces apoptosis in human cervical cancer cell line HeLa cells, Immunopharmacol. Immunotoxicol. 35 43-51.

[21] T. Fukuda, H. Ito, T. Mukainaka, H. Tokuda, H. Nishino and T. Yoshida (2003). Anti-tumor promoting effect of glycosides from Prunus persica seeds, Biol Pharm Bull. 26 271-273.

[22] Z. Song and X. Xu (2014). Advanced research on anti-tumor effects of amygdalin, J. Can. Res. Ther. 10 3-7.

[23] N. Chaouali, I. Gana, A. Dorra, F. Khelifi, A. Nouioui, W. Masri, I. Belwaer, H. Ghorbel and A. Hedhili (2013). Potential toxic levels of cyanide in almonds (Prunus Amygdalus), apricot kernels (Prunus Armeniaca), and almond syrup, ISRN Toxicology 2013 610648-610654.

[24] M.H.F. Shalayel and B. Laetrile (2017). (Vitamin B-17) Controversy-antitumor illusion or revolution, Br. Med. Bull., 5 296-297.

[25] R. A. Blaheta, K. Nelson, A. Haferkamp and E. Juengel (2016). Amygdalin, quackery or cure? Phytomedicine 23 367376.

[26] P. Liczbiński and B. Bukowska (2018) Molecular mechanism of amygdalin action in vitro: review of the latest research, Immunopharmacol. Immunotoxicol. 40 212-218.

[27] C. C. Stock, D.S. Martin, K. Sugiura, R.A. Fugmann, I.M. Mountain, E.Stockert, F.A. Schimid and G.S. Tarnowski. (1978). Antitumor tests of amygdalin in spontaneous animal tumor systems, J. Surg. Oncol. 10, 89-123.

[28] C. G. Moertel, T.R. Fleming, J. Rubin, L.K. Kvols, G.Sarna, R.Koch, V.E. Currie, C.W. Young, S.E. Jonesand J.O. Davignon (1982). A clinical trial of amygdalin (Laetrile) in the treatment of human cancer, N. Engl. J. Med. 306 201206.

[29] B. Mosayyebi, M. Imani, L. Mohammadi, A. Akbarzadeh, N. Zarghami, M. Edalati, E. Alizadeh and N. Rahmati (2020), An update on the toxicity of cyanogenic glycosides bioactive compounds: Possible clinical application in targeted cancer therapy, Mater. Chem. Phys. 246 122841-122848. 
[30] E. Marian, B. Tita, I. C. Tita, T. Jurca and L. Vicas (2018). Thermal behaviour and kinetic study of amygdalin, J. Therm. Anal. Calorim. 134 765-772.

[31] R. C. Weast, (ed.). Handbook of chemistry and physics. 60th ed. Boca Raton, Florida: CRC Press Inc., 1979, p. C-111.

[32] I. F. Bolarinwa, C. Orfila and M.R.A. Morgan, (2014). Amygdalin content of seeds, kernels and food products commercially-available in the UK, Food Chem. 152 133-139.

[33] https://www.chemicalbook.com/CASEN_29883-15-6.htm\#SpectrumDetail (accessed 27 September 2020).

[34] A. A. Ribeiro (1990). ${ }^{1} \mathrm{H}$ and ${ }^{13} \mathrm{C}$ NMR analysis of D-amygdalin: oligosaccharide assignment and sequencing, Magn. Reson. Chem. 28 765-773.

[35] I. M. Savic, V. D. Nikolic, I. M. Savic-Gajic, L. B. Nikolic, S. R. Ibric and D. G. Gajic (2015). Optimization of technological procedure for amygdalin isolation from plum seeds (Pruni Domesticate Semen), Front. Plant Sci. 6 276287.

[36] https://www.acs.org/content/acs/en/molecule-of-the-week/archive/a/amygdalin.html (accessed 27 September 2020).

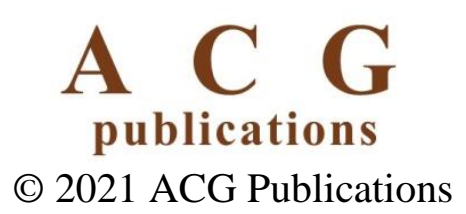

